\section{Evaluasi Geometri Jalan Persimpangan di Kawasan Kampus Universitas Borneo Tarakan}

\section{Muhammad Djaya Bakri}

Program Studi Teknik Sipil, Universitas Borneo Tarakan, Kalimantan Utara

\section{jayabakri@borneo.ac.id}

\section{Pendahuluan}

Setiap tahun volume lalu lintas di dalam kawasan kampus Universitas Borneo Tarakan bertambah seiring dengan peningkatan jumlah penerimaan mahasiswa baru dan pembukaan program studi baru yang juga berpengaruh terhadap peningkatan jumlah mahasiswa. Peningkatan volume lalu lintas ini mengakibatkan kapasitas jalan menjadi berkurang dan rawan kecelakaan, terutama pada area pertigaan jalan, seperti pada trase pertigaan jalan poros menuju kampus fakultas ekonomi, gedung perpustakaan dan gedung FKIP. Oleh karena itu diperlukan peningkatan pada aspek kapasitas jalan, salahsatunya evaluasi kondisi real dari geometri jalan tersebut apakah telah memenuhi peraturan Bina Marga untuk jalan kota tahun 1992, dan bagaimana usulan perbaikan pada geometri persimpangannya.

Pada penelitian ini, lokasi ditinjau dilakukan pada trase pertigaan jalan poros menuju kampus fakultas ekonomi, gedung perpustakaan dan gedung FKIP.

\section{Metode}

Langkah awal yang dilakukan adalah pengambilan data di lapangan dengan melakukan pengamatan secara langsung dan melakukan pengukuran jarak, lebar, dan kemiringan jalan dan aspek pendukung lainnya. Data yang diperoleh selanjutnya diolah dengan menggunakan program Autocad 2014 sehingga memudahkan dalam proses analisis. Gambar 1 memperlihatkan lokasi penelitian dilakukan
Tulisan ini dibuatkan berdasarkan hasil pengamatan dan pengukuran di lapangan terhadap kondisi salah satu persimpangan jalan yang ada di kawasan kampus Universitas Borneo Tarakan yaitu pada trase pertigaan jalan poros menuju kampus Fakultas Ekonomi, gedung perpustakaan dan gedung FKIP. Tujuan evaluasi untuk mengetahui apakah geometri jalan pada persimpangan telah memenuhi peraturan Bina Marga, dan bagaimana usulan perbaikan pada geometri persimpangannya. Penelitian ini dilakukan dengan melakukan pengambilan data di lapangan secara langsung dan melakukan pengukuran jarak, lebar, dan kemiringan jalan, serta aspek pendukung lainnya. Hasil evaluasi menunjukkan bahwa bentuk geometri persimpangan telah memenuhi peraturan yang ditetapkan Ditjen Bina Marga, tetapi masih memerlukan perbaikan untuk lebar jalan pada daerah tikungan dan perlu adanya traffic calming pada area tikungan sebagai pengendali kecepatan kendaraan untuk mereduksi kerawanan terhadap kecelakaan.

Kata kunci: geometri jalan, persimpangan, Ditjen Bina Marga, traffic calming

Diajukan: 10 Juli 2019

Direvisi: 13 Juli 2019

Diterima:18 Juli 2019

Dipublikasikan online:20 Juli 2019
Rangkaian pengambilan data yang dilakukan di lapangan adalah sebagai berikut:

\section{Pengukuran Geometri Jalan Lurus}

Pada tahap ini dilakukan pengukuran geometri jalan, meliputi lebar jalan, kelandaian memanjang dan melintang, dan pengamatan jenis kendaraan, kemudian data yang diperoleh akan dihitung dengan menggunakan rumus (Sukirman, 1999):

Dimana:

$$
L(\min )=[(n . W t)+\{(n+1)(1 / 2 . W t)\}]
$$

$L(\min )=$ lebar minimum pada jalur lurus $(\mathrm{m})$

$\mathrm{N} \quad=$ jumlah jalur

$\mathrm{Wt} \quad=$ lebar satu unit kendaraan $(\mathrm{m})$

\section{Pengukuran Geometri Jalan pada Tikungan}

Geometri jalan tikungan berupa lebar jalan, kelandaian melintang jalan diukur dengan menggunakan alat ukur pemetaan berupa Teodolite Total Station. Data yang diperoleh akan dihitung dengan menggunakan rumus (Sukirman, 1999):

$$
\begin{aligned}
\text { Wmin } & =\{(2 \times(\mathrm{U}+\mathrm{Fa}+\mathrm{Fb}+\mathrm{Z}))+\mathrm{C}\} \\
\mathrm{Z} & =\{(\mathrm{U}+\mathrm{Fa}+\mathrm{Fb}) / 2\}
\end{aligned}
$$

Dimana:

Wmin = lebar jalan pada jalur tikungan $(\mathrm{m})$

$\mathrm{U} \quad=$ jarak jejak roda kendaraan $(\mathrm{m})$

$\mathrm{Fa} \quad=$ panjang tergantung depan $(\mathrm{m})$

$\mathrm{Fb} \quad=$ panjang tergantung belakang $(\mathrm{m})$

$\mathrm{Z} \quad=$ jarak sisi luar kendaraan ke tepi jalan $(\mathrm{m})$

$\mathrm{C}=$ jarak antar kendaraan $(\mathrm{m})$

Cara mensitasi artikel ini:

Bakri, M.D (2019) Evaluasi Geometri Jalan Persimpangan di Kawasan Kampus Universitas Borneo Tarakan. Buletin Profesi Insinyur 2(1) 012-015 


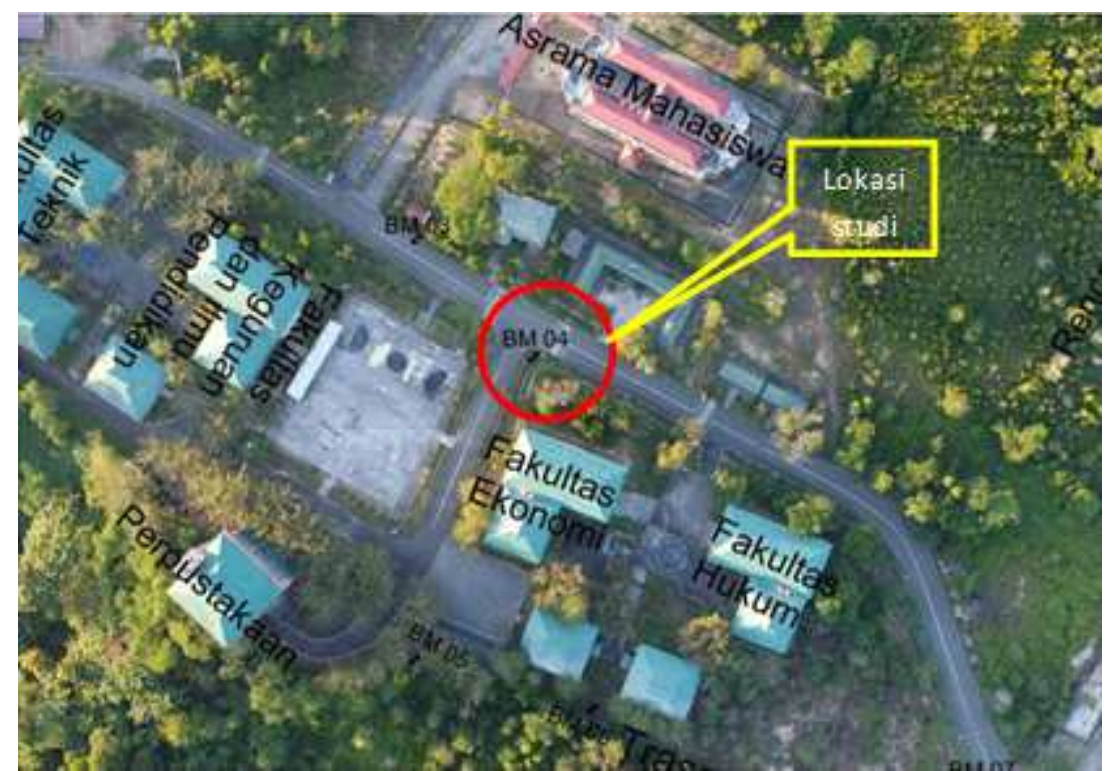

Gambar 1 Lokasi pertigaan jalan poros menuju gedung kampus fkip, gedung fakultas ekonomi dan gedung perpustakaan

\section{Pengukuran Profil Memanjang}

Hasil pengukuran profil memanjang akan dipergunakan menghitung kelandaian jalan. Data yang diperoleh akan dihitung dengan menggunakan rumus (Aldiayansyah et al, 2016):

$$
\text { Grade }=(\text { Beda Tinggi } \times 100 \%) / \mathrm{Jarak}
$$

Dimana:

Kemiringan memanjang (grade) (\%)

Beda Tinggi

Jarak

\section{Karakteristik Geometrik Jalan Pada Persimpangan}

Menurut Abubakar, et al., (1995) dalam Fambella, et al (2014), geometrik persimpanganan harus dirancang sehingga mengarahkan pergerakan (manuver) lalu lintas ke dalam lintasan yang paling aman dan paling efisien, dan dapat memberikan waktu yang cukup bagi para pengemudi untuk membuat keputusan-keputusan yang diperlukan dalam mengendalikan kendaraannya.

\section{Hasil Kerja}

\section{Tinjauan Teknis Geometri Jalan Pada Pertigaan}

Geometri pertigaan jalan yang diamati pada jalan lurus dan tikungan, dan kemiringan memanjang (grade). Panjang lengan jalan pada persimpangan pertigaan yang diamati sepanjang 50 meter. Hasil pengukuran seperti disajikan pada Gambar 2.

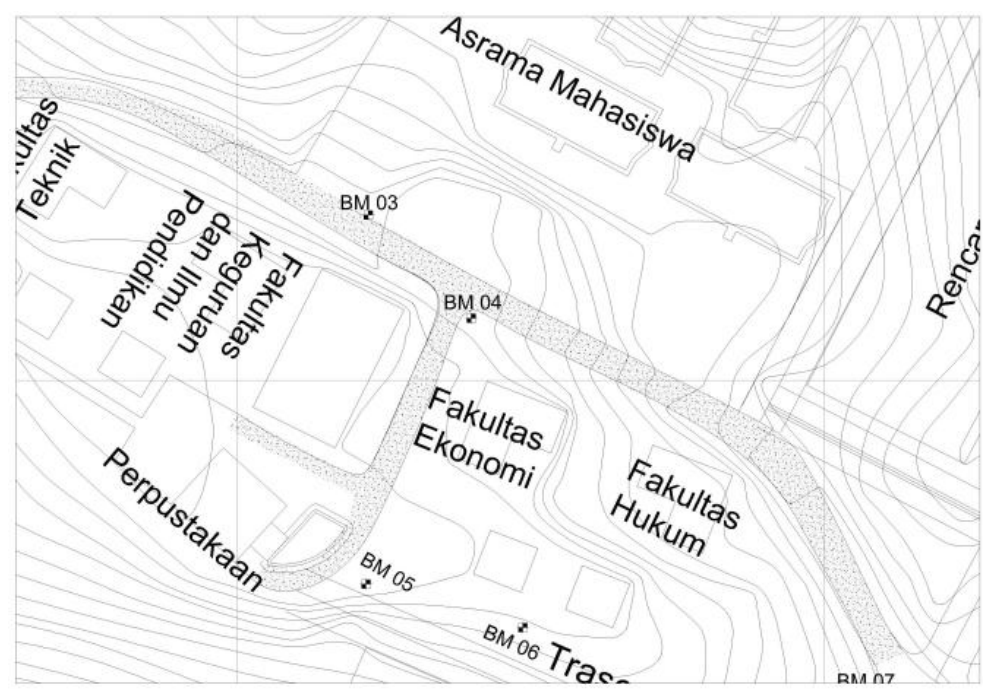

Gambar 2 Geometri Pertigaan Jalan dan Penampang Memanjang Jalan Lurus 


\section{Lebar Jalan Pada Jalan Lurus}

Hasil pengukuran lapangan menunjukkan bahwa jalan di lingkungan kampus UBT merupakan jalan 2 lajur 2 arah tidak terbagi ( $2 / 2$ UD), dimana masing-masing lajur memiliki lebar sebesar 3,5 meter pada jalan poros, dan lebar masing-masing lajur sebesar 3,0 meter pada lengan pertigaan menuju Gedung Perpustakaan seperti ditunjukkan pada Gambar 3.

Spesifikasi kendaraan yang digunakan untuk evaluasi lebar jalan lurus yang ideal, adalah kendaraan penumpang (sesuai standar Bina Marga) yang banyak melintas di kawasan kampus. Perhitungan menggunakan Persamaan 1, sebagai berikut:

Untuk penentuan jalan lurus dengan 1 jalur:

$\operatorname{Lmin}=(1 \times 1,7)+(1+1)(0,5 \times 1,7)=\mathbf{3 , 4} \mathbf{~ m}$

Jadi lebar jalan lurus dengan 1 jalur adalah $3,4 \mathrm{~m}$

Untuk penentuan jalan lurus dengan 2 jalur:

$\operatorname{Lmin}=(2 \times 1,7)+(2+1)(0,5 \times 1,7)=6,8 \mathrm{~m}$

Jadi lebar jalan lurus untuk 2 jalur adalah $6,8 \mathrm{~m}$

\section{Lebar Jalan Pada Tikungan}

Hasil pengukuran lapangan diperoleh lebar jalan ditikungan selebar 8,2 meter. Untuk penentuan lebar jalan pada tikungan dihitung dengan Persamaan 2. Untuk penentuan lebar jalan tikungan dengan 1 jalur:
Wmin $=1((1,3+0,8+1,2+)+2,35)=\mathbf{5 , 6 5} \mathbf{m}$

Jadi lebar jalan tikungan dengan 1 jalur adalah 5,65 m.

Untuk penentuan lebar jalan tikungan dengan 2 jalur:

$\left.\mathbf{W m i n}_{\mathbf{m}} 2(1,3+0,8+1,2+)+2,35\right)=\mathbf{8 , 9 5} \mathbf{~}$.

Jadi lebar jalan lurus dengan 2 jalur adalah $8,95 \mathrm{~m}$.

\section{Tingkat Kemiringan Memanjang (Grade)}

Hasil pengukuran lapangan diperoleh bentuk kemiringan jalan pada jalur poros seperti ditampilkan pada Gambar 4 lebar jalan ditikungan selebar 8,2 meter.

Perhitungan kemiringan memanjang menggunakan Persamaan 4, sebagai berikut:

Grade $=(37-32 \times 100 \%) / 80=6,25 \%$

\section{Evaluasi Geometrik Persimpangan}

Evaluasi geometrik persimpangan dilakukan pada trase pertigaan jalan poros menuju kampus fakultas ekonomi, gedung perpustakaan dan gedung FKIP, yang merupakan persimpangan tiga kaki. Hasil penelitian Fambella, dkk (2014), memberikan rujukan bahwa geometrik persimpangan harus dirancang dengan baik sehingga dapat mengarahkan pergerakan (manuver) lalu lintas ke dalam lintasan yang paling aman dan paling efisien .

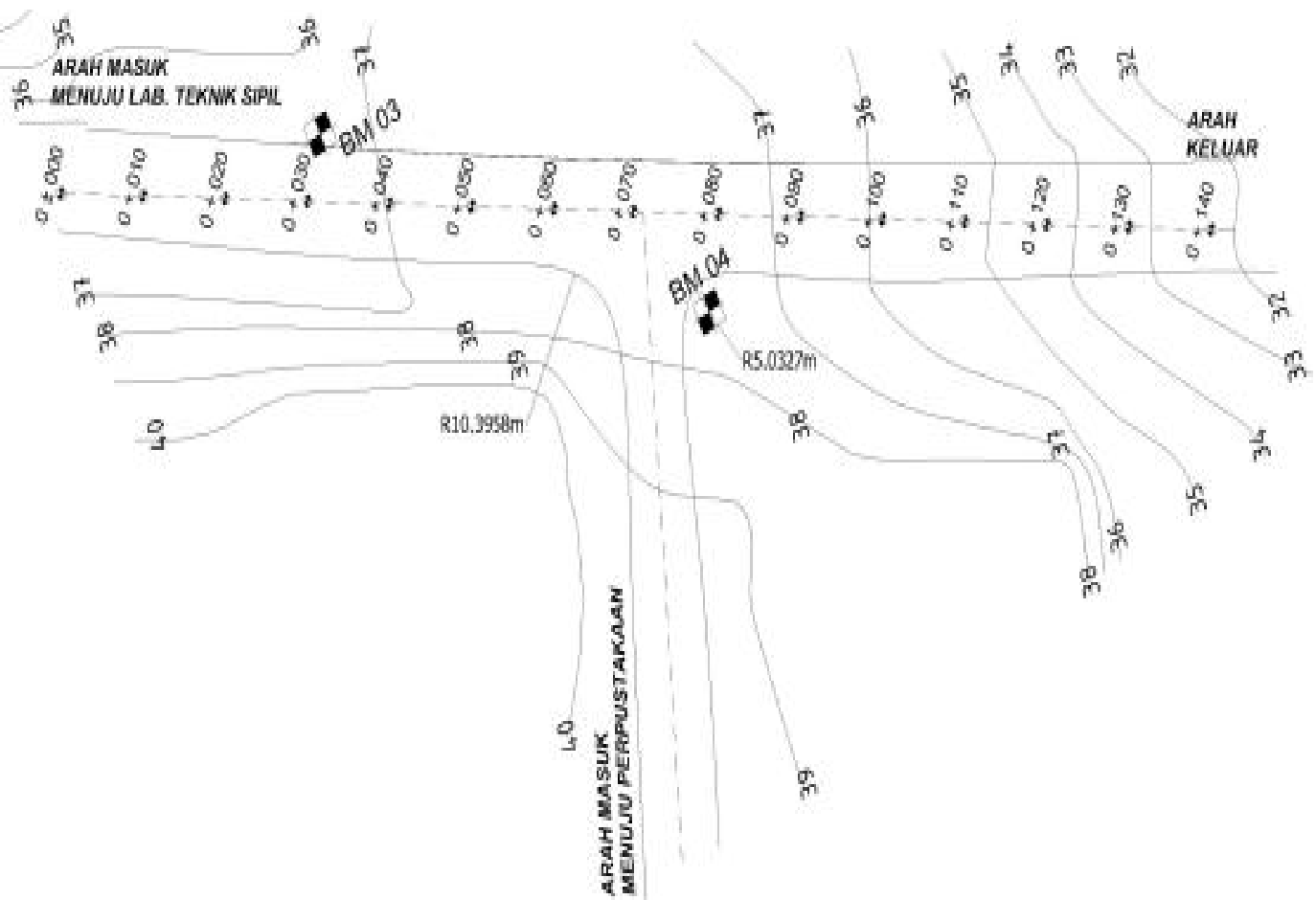

Gambar 3 Kondisi Geometri Eksisting Pertigaan Jalan 


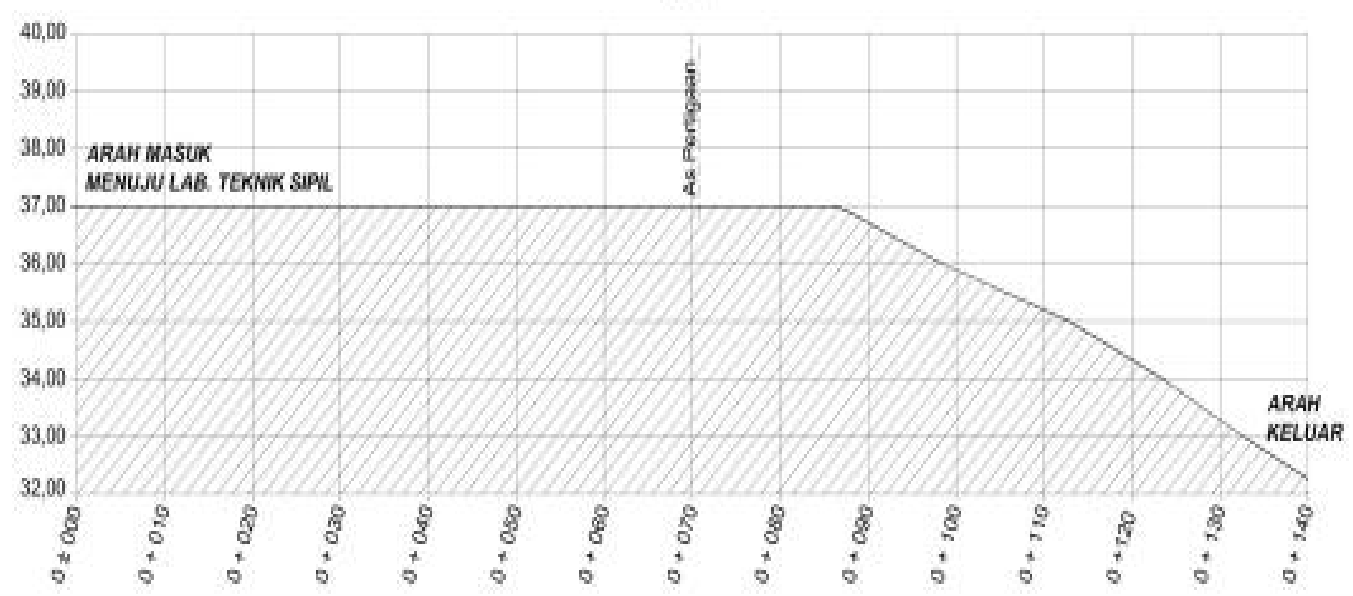

Gambar 4 Penampang memanjang jalan poros pada perpersimpangan

Analisis geometrik persimpangan dilakukan dengan mengacu pada peraturan resmi yang dikeluarkan Ditjen Bina Marga, yaitu Standard Perencanaan Geometrik untuk Jalan Kota tahun 1992 dan Pt T-02-2002-B Tata Cara Perencanaan Geometrik Persimpangan Sebidang. Sesuai dengan Pt T-02-2002-B semua persimpangan sebidang dimana pertemuan lengan dengan lengan harus saling tegak lurus $(\perp)$, toleransi sudut $/ \alpha$ bisa sampai $\pm 20^{\circ}$. Dari analisis didapatkan bahwa persimpangan trase pertigaan jalan poros menuju kampus fakultas ekonomi, gedung perpustakaan dan gedung FKIP memenuhi syarat pertemuan lengan, tetapi lebar jalan di persimpangan belum memenuhi syarat sehingga perlu dilakukan pelebaran jalan ditikungan untuk memberikan kenyamanan pada saat manuver kendaraan.

\section{Kesimpulan}

Dari hasil evaluasi dapat disimpulkan beberapa hal sebagai berikut:

1. Geometri jalan lurus pada jalan poros dari hasil pengukuran menunjukkan lebar masing-masing jalur jalan sebesar 3,5 meter telah memenuhi lebar yang dipersyaratkan yaitu 3,4 meter, sedangkan pada lengan jalan persimpangan belum memenuhi syarat karena lebar jalurnya adalah sebesar 3,0 meter ( $<3,4$ meter).

2. Lebar jalan pada pada tikungan dari pengukuran di lapangan diperoleh sebesar 8,2 meter, sedangkan hasil analisis membutuhkan lebar sebesar 8,95 meter.

3. Kemiringan jalan pada jalan poros sebesar $6,25 \%$ telah memenuhi persyaratan kelandaian jalan dalam kawasan pendidikan dengan kecepatan rencana $30 \mathrm{Km} / \mathrm{jam}$ dan syarat kelandaian $8 \%$.

4. Bentuk lengan pada perpersimpangan sudah memenuhi peraturan yang ditetapkan Dirjen Bina Marga, yaitu Standard Perencanaan Geometrik untuk Jalan Kota tahun 1992 dan Pt T-02-2002-B Tata Cara Perencanaan Geometrik Persimpangan Sebidang.

\section{Rekomendasi}

Rekomendasi perbaikan persimpangan jalan tersebut, sebagai berikut:

1. Pada tikungan perlu dilakukan pelebaran pada kedua sisi sesuai kebutuhan lebar jalan agar dapat mengarahkan pergerakan lalu lintas yang lebih aman dan efisien.

2. Permukaan jalan memasuki tikungan perlu dipasang traffic calming berupa rumble strip atau dikenal sebagai pita penggaduh untuk mengurangi kecepatan kendaraan ketika memasuki area perpersimpangan.

\section{Ucapan Terima Kasih}

Ucapan terimakasih kepada rekan sejawat dan mahasiswa Program Studi Teknik Sipil Fakultas Teknik Universitas Borneo Tarakan yang telah membantu mengumpulkan data lapangan.

\section{Referensi}

Aldiyansyah, Husain, J.R., Nurwaskito, A., Analisis Geometri Jalan di Tambang Utara Pada PT. IFISHDECO Kecamatan Tinanggea Kabupaten Konawe Selatan Provinsi Sulawesi Tenggara, Jurnal Geomine, Vol 4 No. 2 (2016): 71-75

Anonim, Tata Cara Perencanaan Geometrik Jalan Kota, Ditjen Bina Marga, Jakarta, 1992.

Anonim, Peraturan Menteri Pekerjaan Umum Nomor: Pt T-02-2002-B Tahun 2002 tentang Tata Cara Perencanaan Geometrik Persimpangan Sebidang, Departemen Pekerjaan Umum, Jakarta, 2002.

Fambella, B.C., Sulaksitaningrum, R., Arifin, M.Z., Bowoputro, H., Evaluasi dan Perencanaan Geometrik Jaringan Jalan di Dalam Universitas Brawijaya Malang, Jurnal Mahasiswa Jurusan Teknik Sipil Fakultas Teknik Universitas Brawijaya, Vol 1 No. 3 (2014): 1146-1154.

Sukirman, S., Dasar-dasar Perencanaan Geometrik Jalan, Penerbit Nova Bandung, 1999. 